\title{
Communication
}

\section{Synthesis of Novel Asymmetric Zinc (II) Phthalocyanines Bearing Octadecyloxyl and Glucosyl Groups}

\author{
Pei Zhang, Shufen Zhang * and Gang Han
}

State Key Laboratory of Fine Chemicals, Dalian University of Technology, Dalian 116012, China E-Mails: spaceswimer@hotmail.com (P.Z.); hangangxiaoxi@hotmail.com (G.H.)

* Author to whom correspondence should be addressed; E-Mail: zhangshf@dlut.edu.cn; Tel.: +8641139893621; Fax: +8641139893800.

Received: 23 July 2009; in revised form: 31 August 2009 / Accepted: 8 September 2009 / Published: 18 September 2009

\begin{abstract}
A novel asymmetric zinc (II) phthalocyanine substituted by one lipophilic octadecyloxyl group and three hydrophilic glucosyl groups was synthesized. Using Q-TOF MS, the major byproducts formed during the deprotection processes were identified. An improved procedure was worked out to convert these byproducts to the desired product in quantitative yield.
\end{abstract}

Keywords: carbohydrates; phthalocyanine; asymmetric; deprotection

\section{Introduction}

Photodynamic therapy (PDT) has attracted increasing attention as a treatment for cancer in recent years [1-8], and photosensitizers play a critical role in this therapy. With a strong absorption at the red light region, the ability to generate singlet oxygen efficiently, and a long excitation wavelength which enables it to act deep under the skin, phthalocyanine is an ideal parent structure for a photosensitizer $[9,10]$. However, the poor aqueous solubility of phthalocyanine significantly limits its application in PDT. To improve its solubility, an ionic modification of phthalocyanine was made [11], but this failed to give the desired results. The resulting derivative also failed to meet the requirement of selective absorption by tumor cells. Compared to normal cells, tumor cells require more glucose as an energy supply. Additional glucose as a handle might assist penetration into target cells with the help of the functional glucose transporters on the cell membrane [12]. Thus, glucoconjugation of photosensitizers 
was expected to increase their selective absorption by tumor cells and their transportation through cell membranes. Glucoconjugated phthalocyanine was first reported in 1989 [13], followed in recent years by silicon(IV) phthalocyanines with one or two axial acetal-protected galactose substituents [14], glucose substituted zinc(II) phthalocyanine linked via the anomeric carbon [15], asymmetrical zinc(II) phthalocyanine with four galactose substituents [16], glycosylated zinc(II) phthalocyanines through O or S [17], octasubstituted galactose zinc(II) phthalocyanine [18], and amphiphilic Ni phthalocyanines bearing a hydrophilic galactose head facing six hydrophobic thiohexyl chains [19]. Amphiphilic capacity is an important factor in the design of photosensitizer due to the hydrophobic nature of the lipid membrane [20,21]. In our work, an asymmetrical zinc (II) phthalocyanine bearing three glucosyl groups and an octadecyloxyl group was designed and synthesized. Our synthetic methodology allows ready modulation of the amphiphilic capacity of phthalocyanines by changing the alkoxyl groups, which will provide a base for further studies in the impact of amphiphilic capacity on photosensitizer effects in PDT.

\section{Results and Discussion}

The preparation of asymmetric phthalocyanine 4 is shown in Scheme 1. Firstly, protected glucosyl phthalonitrile 1 (hydrophilic monomer) and octadecyloxyl phthalonitrile 2 (lipophilic monomer) were synthesized by nucleophilic substitution [13]. Phthalocyanine 3 was then obtained by statistical crosscondensation in the presence of zinc chloride and DBU (1,8-diazabicyclo[5.4.0]undec-7-ene) under nitrogen at $100{ }^{\circ} \mathrm{C}[22,23]$. According to a probabilistic calculation, the highest theoretical yield is reached when the molar ratio of the hydrophilic monomer to the lipophilic monomer is $3: 1$. The reaction gave a series of phthalocyanines with different numbers of glucosyl and octadecyloxyl groups. The desired product $\mathbf{3}$ was isolated by silica gel column chromatography eluted with a gradient of ethyl acetate and toluene.

Scheme 1. Synthesis of [2(3), 9(10), 16(17)-tris(glucosyl)-23(24)-octadecyloxyl phthalocyaninato] zinc (II) (4).

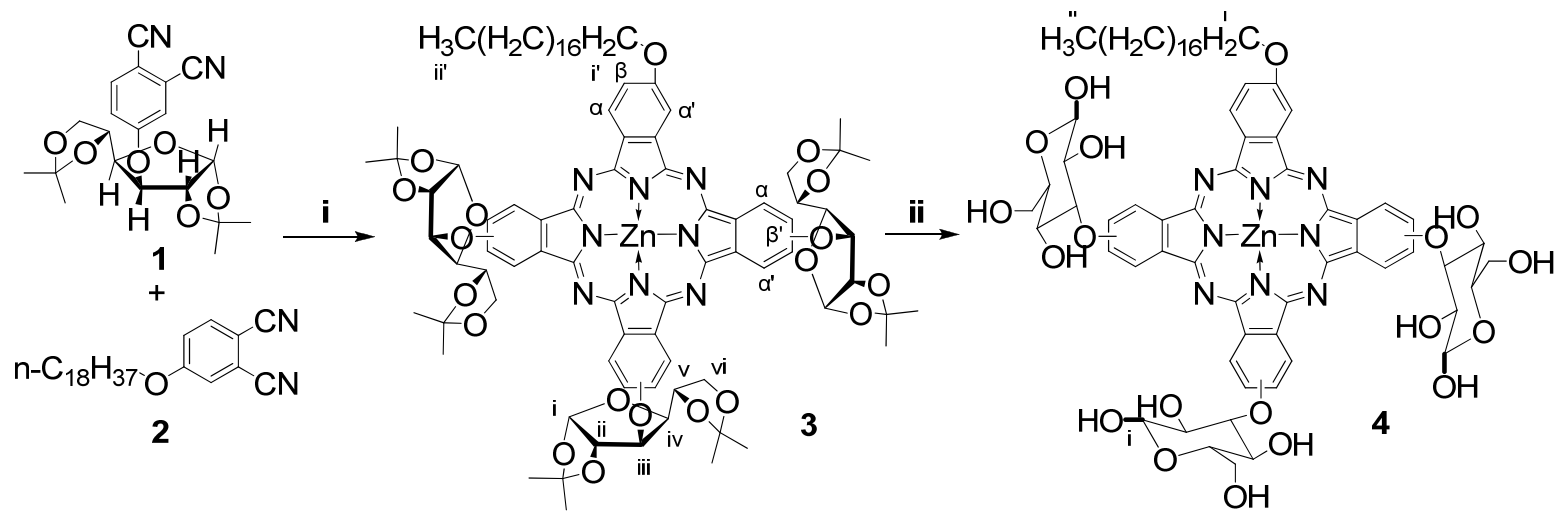

Reactions and conditions: (i) $\mathrm{ZnCl}_{2}$, DBU, DMAE, $\mathrm{N}_{2}, 100^{\circ} \mathrm{C}, 11 \mathrm{~h}$; (ii) a. TFA $/ \mathrm{H}_{2} \mathrm{O}(9: 1), 0{ }^{\circ} \mathrm{C}, 4$ h, b. Pyridine $/ \mathrm{MeOH}, 25^{\circ} \mathrm{C}, 4 \mathrm{~h}$.

The deprotection of compound $\mathbf{3}$ was initially carried out as follows: a sample of $\mathbf{3}$ in trifluoroacetic acid (TFA) $/ \mathrm{H}_{2} \mathrm{O}\left(9 / 1 \mathrm{v} /\right.$ vwas stirred in the dark at $20^{\circ} \mathrm{C}$ for $30 \mathrm{~min}$; then the reaction mixture was poured into toluene and rapidly evaporated under reduced pressure [16]. The product mixture was 
complicated and difficult to purify [23]. Thus it was analyzed by Q-TOF MS directly without further refinement. According to the Q-TOF results shown in Figure 1, in addition to the signal of the desired product $4(\mathrm{~m} / \mathrm{z}$ 1,379), there are several signals $(\mathrm{m} / \mathrm{z} 1,419,1,475$ and 1,515) that may be attributed to compound 4 with one isopropylidene residue (M+40), TFA-esterified compound $4(\mathrm{M}+96)$ and TFAesterified compound 4 with one isopropylidene residue $(\mathrm{M}+40+96)$, respectively. This indicates that the hydroxyl group had been esterified by TFA under the deprotection conditions. After several attempts at optimizing the deprotection conditions including changes in sample concentrations, the ratio of TFA $/ \mathrm{H}_{2} \mathrm{O}$ and reaction temperature and time, esterification by TFA still occurred before the deprotection was complete.

Figure 1. Typical Q-TOF mass spectrum of raw products of compound 3 after deprotection reaction.

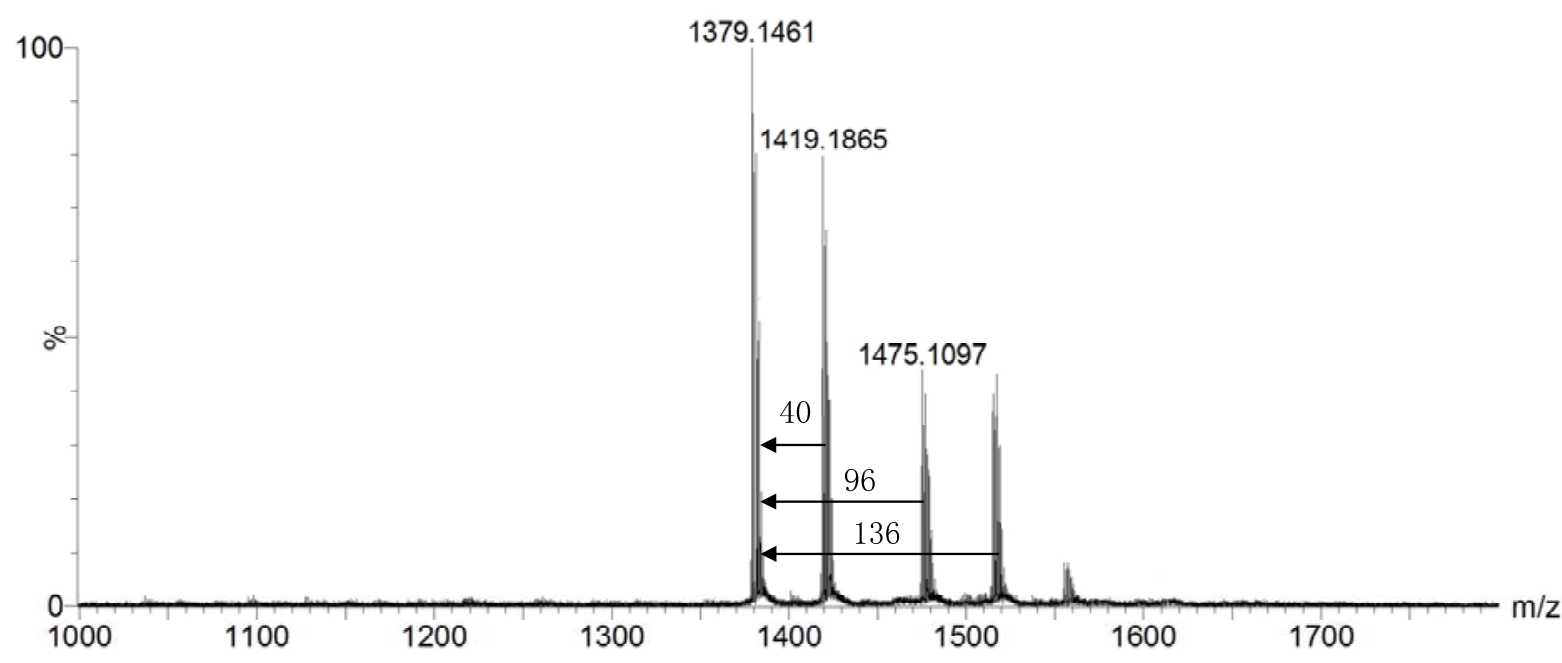

TFA esters undergo hydrolysis under alkaline conditions [24]. In our further attempts to optimize the synthesis, this was used to effect the deprotection of compound $\mathbf{3}$ by a two-step method. First, the sample was treated with TFA/ $\mathrm{H}_{2} \mathrm{O}(9 / 1, \mathrm{v} / \mathrm{v})$ to remove the isopropylidene group, then the mixture was stirred in pyridine/ $\mathrm{MeOH}(1 / 30, \mathrm{v} / \mathrm{v})$ to remove the trifluoroacetyl group. The desired compound $\mathbf{4}$ was then obtained in quantitative yield by evaporating the solution under reduced pressure.

The definitive characterization of compound 3 and $\mathbf{4}$ was achieved using Q-TOF MS. As a mixture of isomers, the ${ }^{1} \mathrm{H}-\mathrm{NMR}$ spectrum of compound 3 in a mixture of $\mathrm{CDCl}_{3}$ and pyridine- $\mathrm{d}_{5}(20 / 1, \mathrm{v} / \mathrm{v})$ was in agreement with that of the phthalocyanine parent structure bearing protected glucosyl [24] or alkoxyl [25] groups with long carbon chains. It shows three broad signals between 9.45 and 8.65 ppm due to the resonance of Pc $\alpha-\mathrm{H}$ or $\alpha$ '-H (Scheme 1) because there are two kinds of substituent linked to phthalocyanine. For the same reason, two broad signals between 7.95 and $7.45 \mathrm{ppm}$ were assigned to the resonances of Pc $\beta-\mathrm{H}$ (Scheme 1). The ${ }^{1} \mathrm{H}-\mathrm{NMR}$ spectrum of compound 4 in $\mathrm{DMSO}-\mathrm{d}_{6}$ was consistent with a phthalocyanine structure substituted by deprotected glucosyl $[15,16]$ or alkoxyl [25] groups with long carbon chains, the signals corresponding to proton $\mathrm{H}-\mathrm{i}$ of the glucosyl moieties (in $\alpha$ and $\beta$-configurations) appeared at 6.75 and $6.95 \mathrm{ppm}$. UV-Vis spectrum of compound 4 in $\mathrm{MeOH}$ was a typical spectrum of phthalocyanine which had a sharp Q-band at $680 \mathrm{~nm}$. 


\section{Experimental}

\subsection{General methods}

For column chromatography, E. Merck 60G Silica Gel was used. ${ }^{1} \mathrm{H}$ - and ${ }^{13} \mathrm{C}-\mathrm{NMR}$ spectra were recorded at ambient temperature using a Varian INOVA spectrometer. Chemical shift values were reported in $\mathrm{d}(\mathrm{ppm})$ relative to $\mathrm{Me}_{4} \mathrm{Si}$. ESI-Q-Tof mass spectra (ESIMS) were measured using a Micromass UPLC/Q-Tof Mass Spectrometer. All reagents were of commercial quality and were purified according to general procedures.

\subsection{Synthesis of [2(3),9(10),16(17)-tris(1,2:5,6-di-O-isopropylidene-a-D-glucofuranosyl)-23(24)-} octadecyloxyl phthalocyaninato] zinc (II) (3)

Phthalonitrile 1 (2.4 g, $6 \mathrm{mmol})$, phthalonitrile $2(0.8 \mathrm{~g}, 2 \mathrm{mmol})$ and $\mathrm{ZnCl}_{2}(0.3 \mathrm{~g}, 2 \mathrm{mmol})$ in DMAE $(25 \mathrm{~mL})$ were stirred at $100{ }^{\circ} \mathrm{C}$ under a $\mathrm{N}_{2}$ atmosphere for $12 \mathrm{~h}$. After cooling, the mixture was poured into water $(500 \mathrm{~mL})$ and the solid was filtered. The crude product was purified by chromatography over silica gel [eluent: EtOAc/toluene, 80:20] to give 3. Yield $0.8 \mathrm{~g}(25 \%)$. ${ }^{1} \mathrm{H}-\mathrm{NMR}$ $\left(\mathrm{CDCl}_{3}+\right.$ pyridine- $\left.\mathrm{d}_{5}\right): \delta=9.45-8.65$ and 7.95-7.45 (12H, Pc-H), $6.20(3 \mathrm{H}, \mathrm{H}-\mathrm{i}), 5.46-5.35$ (3H, H-iii), 5.06 (3H, H-ii), 4.81 (3H, H-v), 4.68-4.48 (3H, H-iv), 4.41-4.27 (8H, H-vi H-i’), 1.80-1.12 (68H, $\left.\mathrm{OCH}_{3}, \mathrm{CH}_{2}\right), 0.87$ (3H, H-ii'); ${ }^{13} \mathrm{C}-\mathrm{NMR}\left(\mathrm{CDCl}_{3}+\text { pyridine-d }\right)_{5}: \delta=158.85,140.59,140.45,132.89$, $131.39,130.86,130.21,129.99,129.71,128.83,128.11,127.93,118.55,112.45,109.38,105.65$, $82.80,81.03,72.60,69.01,67.38,65.51,62.12,34.03,31.91,30.60,29.73,29.33,29.12,27.21,27.03$, 26.51, 26.38, 25.66, 25.42, 24.88, 22.66, 19.18, 14.07, 13.68; UV-vis $\left(\mathrm{CHCl}_{3}\right) \lambda_{\max }(\log \varepsilon): 347$ (4.89), 616 (4.51), 681 (5.09) nm; HRMS (Q-TOF): $\mathrm{m} / \mathrm{z}=1620.9790(\mathrm{M}+\mathrm{H})^{+}$.

\subsection{Synthesis of [2(3), 9(10), 16(17)-tris(glucosyl)-23(24)-octadecyloxyl phthalocyaninato] zinc (II) (4)}

Phthalocyanine $3(10 \mathrm{mg}, 6.2 \mathrm{mmol})$ in TFA $/ \mathrm{H}_{2} \mathrm{O}(9 / 1, \mathrm{v} / \mathrm{v}, 4 \mathrm{~mL})$ was stirred in the dark at $0{ }^{\circ} \mathrm{C}$ for $4 \mathrm{~h}$, the reaction mixture was rapidly co-evaporated with toluene $(50 \mathrm{~mL})$ under reduced pressure, then the solid was stirred in the mixture DMF $(0.1 \mathrm{~mL})$ and pyridine/ $\mathrm{MeOH}(1 / 30, \mathrm{v} / \mathrm{v}, 1 \mathrm{~mL})$ in the dark at $25^{\circ} \mathrm{C}$ for $4 \mathrm{~h}$. The product was obtained by evaporation under reduced pressure. ${ }^{1} \mathrm{H}-\mathrm{NMR}$ (DMSO- $\mathrm{d}_{6}$ ): $\delta=9.40-8.80$ and 7.94-7.70 (12H, Pc-H), 6.75 and 6.95 (3H, H-i), 5.72-3.45 (32H, Glu-H H-i') 2.08$\left.1.08\left(32 \mathrm{H}, \mathrm{CH}_{2}\right), 0.81\left(3 \mathrm{H}, \mathrm{H}-\mathrm{ii}{ }^{\prime}\right) ;{ }^{13} \mathrm{C}-\mathrm{NMR}\left(\mathrm{CDCl}_{3}+\text { pyridine-d }\right)_{5}\right): \delta=158.24,157.93,157.62$, $157.30,153.17,152.50,140.33,139.93,131.28,128.96,128.13,127.75,122.70,121.52,119.82$, $118.54,115.56,112.58,109.02,96.82,92.55,83.51,76.51,74.42,72.17,71.77,69.65,68.38,60.97$, 31.11, 28.85, 28.51, 25.58, 21.91, 21.31, 13.76; UV-Vis (MeOH) $\lambda_{\max }(\log \varepsilon): 349$ (4.63), 613 (4.25), $680(4.83) \mathrm{nm}$; HRMS (Q-TOF): $\mathrm{m} / \mathrm{z}=1379.3811(\mathrm{M}+\mathrm{H})^{+}$.

\section{Conclusions}

In summary, an asymmetric zinc (II) phthalocyanine with both lipophilic and hydrophilic groups has been synthesized and characterized. The TFA-esterified byproducts formed during the deprotection were characterized and converted into the final product by a two-step method which might find general application in the removal of isopropylidene groups from similar compounds. On 
the basis of this synthetic methodology, a series of asymmetric phthalocyanines with different lipophilic groups could be readily synthesized, which should provide great opportunities to study the impact of amphiphilic capacity on the effect of photosensitizers in PDT.

\section{Acknowledgements}

We gratefully acknowledge financial supports from the National Natural Science Funds for Distinguished Young Scholar of China (Grant No. 20525620) and the Program for Changjiang Scholars and Innovative Research Team in the University (IRT0711).

\section{References and Notes}

1. Dolmans, D.E.J.G.J.; Fukumura, D.; Jain R.K. Photodynamic therapy for cancer. Nat. Rev. Cancer 2003, 3, 380-387.

2. Ochsner, M. Photophysical and photobiological processes in the photodynamic therapy of tumors. J. Photochem. Photobiol. B 1997, 39, 1-18.

3. Dougherty, T.J.; Gomer, C.J.; Henderson, B.W.; Jori, G.; Kessel, D.; Korbelik, M.; Moan, J.; Peng, Q. Photodynamic therapy. J. Natl. Cancer I 1998, 90, 889-905.

4. His, R.A.; Rosenthal, D.I.; Glastein, E. Photodynamic therapy in the treatment of cancer: Current state of the art. Drugs 1999, 57, 725-734.

5. Adams, K.R.; Berembaum, M.C.; Bonnett, R.; Nizhnik, A.N.; Salgado, A. Second generation tumour photosensitisers: The synthesis and biological activity of octaalkyl chlorins and bacteriochlorins with graded amphiphilic character. J. Chem. Soc. Perkin Trans. 1 1992, 1465-1470.

6. Bonnett, R.; Nizhnik, A.N.; White, R.D.; Berembaum, M.C. Porphyrin sensitizers in tumor phototherapy. Novel sensitizers of the chlorin and bacteriochlorin class with amphiphilic properties. J. Photochem. Photobiol. B 1990, 6, 29-37.

7. Bonnett, R. Photodynamic Action. In Advanced Chemistry Texts Chemical Aspects of Photodynamic Therapy; Gordon and Breach Science Publishers: London, UK, 2000; Vol. 1, pp. 130-147.

8. Zheng, G.; Potter, W.R.; Camacho, S.H.; Missert, J.R.; Wang, G.; Bellnier, D.A.; Henderson, B.W.; Rodgers, M.A.J.; Dougherty, T.J.; Pandey, R.K. Synthesis, photophysical properties, tumor uptake, and preliminary in vivo photosensitizing efficacy of a homologous series of 3-(1'Alkyloxy)ethyl-3-devinylpurpurin-18- $N$-alkylimides with variable lipophilicity. J. Med. Chem. 2001, 44, 1540-1559.

9. Bonnet, R.; Martinez, G. Photobleaching of sensitizers used in photodynamic therapy. Tetrahedron 2001, 57, 9513-9547.

10. Macdonald, I.J.; Dougherty, T.J. Basic principles of photodynamic therapy. J. Porphyr. Phthalocya 2001, 5, 105-129.

11. Ogunsipe, A.; Nyokong, T. Photophysical and photochemical studies of sulphonated nontransition metal phthalocyanines in aqueous and non-aqueous media. J. Photochem. Photobiol. A 2005, 173, 211-220. 
12. Brown, R.S.; Wahl, R.L. Overexpression of Glut-1 glucose transporter in human breast cancer. An immunohistochemical study. Cancer 1993, 72, 2979-2985.

13. Maillard, P.; Guerquin-Kern, J.L.; Momenteau, M. Glycoconjugated tetrapyrrolic macrocycles. J. Am. Chem. Soc. 1989, 111, 9125-9127.

14. Lee, P.P.S.; Lo, P.C.; Chan, E.Y.M.; Fong, W.P.; Ko, W.H.; Ng, D.K.P. Synthesis and in vitro photodynamic activity of novel galactose containing phthalocyanines. Tetrahedron Lett. 2005, 46, 1551-1554.

15. Alvarez, M.X.; Calvete, M.J.F.; Hanack, M.; Ziegler, T. The first example of anomeric glycoconjugation to phthalocyanines. Tetrahedron Lett. 2006, 47, 3283-3286.

16. Ribeiro, A.O.; Tomé, J.P.C.; Neves, M.G.P.M.S.; Tomé, A.C.; Cavaleiro, J.A.S.; Iamamotob, Y.;

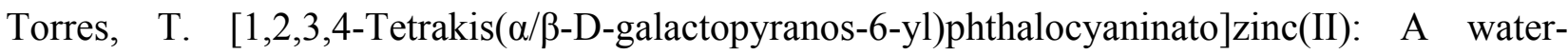
soluble phthalocyanine. Tetrahedron Lett. 2006, 47, 9177-9180.

17. Xavier, Á.M.; Mario J.F.C.; Michael H.; Thomas Z. Expeditious Synthesis of Glycosylated Phthalocyanines. Synthesis 2007, 14, 2186-2192.

18. Zafar, I.; Michael H.; Thomas Z. Synthesis of an octasubstituted galactose zinc(II) phthalocyanine. Tetrahedron Lett. 2009, 50, 873-875.

19. Ufuk, K.; Mahmut, A.E.; Fabienne, D.; Vefa, A. Amphiphilic galactosylated phthalocyanines. J. Porphyr. Phthalocya 2008, 12, 1090-1095.

20. Drain, C.M.; Christensen, B.; Mauzerall, D.C.P. Photogating of ionic currents across a lipid bilayer. Proc. Natl. Acad. Sci. USA 1998, 86, 6959-6962.

21. Drain, C.M.; Mauzerall, D.C. Photogating of ionic currents across lipid bilayers. Hydrophobic ion conductance by an ion chain mechanism. Biophys. J. 1992, 63, 1556-1563.

22. Tomoda, H.; Asito, S. Phosphonates and thiophosphonates as sulfate surrogates: synthesis of estrone 3-methylthiophosphonate, a potent inhibitor of estrone sulfatase. Chem. Lett. 1983, 3, 313-318.

23. Choi, C.F.; Huang, J.D.; Lo, P.C.; Fong, W.P.; Ng., D.K.P. Glycosylated zinc(II) phthalocyanines as efficient photosensitisers for photodynamic therapy. Synthesis, photophysical properties and in vitro photodynamic activity. Org. Biomol. Chem. 2008, 6, 2173-2181.

24. Takatani, M.; Matsuo, I.; Ito, Y. Pentafluoropropionyl and trifluoroacetyl groups for temporary hydroxyl group protection in oligomannoside synthesis. Carbohydr. Res. 2003, 338, 1073-1081.

25. Chauhan, S.; Kumari, P.; Agarwal, S. Efficient synthesis of transition-metal phthalocyanines in functional ionic liquids. Synthesis 2007, 23, 3713-3721.

Sample Availability: Samples of the compounds are available from the authors.

(C) 2009 by the authors; licensee Molecular Diversity Preservation International, Basel, Switzerland. This article is an open-access article distributed under the terms and conditions of the Creative Commons Attribution license (http://creativecommons.org/licenses/by/3.0/). 